\section{Prevalence of hemolytic anemia and hemoglobinopathies among the pregnant women attending a tertiary hospital in central India}

\author{
Ranbir S. Balgir \\ Department of Biochemistry, Regional \\ Medical Research Centre for Tribals \\ (Indian Council of Medical Research), \\ Jabalpur, Madhya Pradesh, India
}

\section{Abstract}

Anemia in pregnancy is one of the causes of maternal morbidity and, maternal and fetal mortality in India. Hemoglobin transports oxygen to different parts of the body. Any defect in hemoglobin structure leads to its adverse functions. Screening of pregnant women for hemoglobinopahties helps in early intervention for reducing morbidity and mortality. Although the prevalence of hemoglobinopathies especially of the sickle cell disorders is high in Madhya Pradesh but any study on pregnant women is lacking. This study had set the objectives to find the prevalence of anemia and hemoglobin disorders in pregnant women, and to determine the health status through hematological indices profile in central India. Hospital based a cross-sectional study showed $12.26 \%$ prevalence of hemoglobinopathies among 416 pregnant women, the sickle cell trait being $7.45 \%$, followed by $\beta$-thalassemia trait (2.89\%), hemoglobin E trait (0.24\%), and sickle cell disease (1.68\%). About $88 \%$ of the pregnant women were found free of hemoglobinopathies. Of the 9.13\% pregnant women included in the study were suffering from sickle cell disorders. However, the overall $47.11 \%$ anemia was observed in pregnant women, ranging in between $45 \%$ to $66 \%$ and seemed to show a reduction in anemia after nutritional supplementations and improvement in maternal health care at antenatal check up due to accessibility to medical health facilities. A comparison of hematological indices of pregnant women afflicted with and without sickle cell disorders have revealed much reduced hemoglobin level, red blood cells count, mean corpuscular volume, hematocrit, and mean corpuscular hemoglobin; and raised leucocytosis in sickle cell disorder cases than among the normal pregnant women. A more vigorous and realistic campaign of prophylactic regime of supplementations for these pregnant women and child health care is suggested.

\section{Introduction}

The people of Central India are at a higher risk for being carriers of hemoglobinopathies especially of the sickle cell disorders and should be offered carrier screening. ${ }^{1,2}$ Although the advances in prenatal diagnosis of hemoglobinopathies have been impressive, the use of technology has somewhat been limited in India because of ethical, social, and cultural concerns. ${ }^{3,4}$ Pregnancies in women with sickle cell disease are at increased risk for intrauterine growth retardation, spontaneous abortion, stillbirth, and preterm labor. ${ }^{3,5-7}$ The magnitude of the risk varies with the degree of defective genotype, nutritional status, severity of anemia, risk of morbidity and mortality because of the combination of underlying hemolytic anemia and multiple organ dysfunctions ${ }^{8,9}$ Early symptoms are usually nonspecific (e.g., fatigue, weakness, light-headedness, mild dyspnoea with exertion). However, hemolytic anemia almost always becomes more severe as pregnancy progresses. ${ }^{10}$

Prevailing high maternal morbidity and mortality have always been a source of medical concern; being antenatal and intra-partum care components of the Family Welfare Program, which are aimed at reducing maternal and fetal morbidity and mortality in India. Of the major causes of maternal mortality, still continue to be the unsafe abortions, antenatal and post-partum haemorrhage, anemia, obstructed labor, hypertensive disorders and post-partum sepsis, among other complications. Hemolytic anemia is a major cause of maternal mortality in India., ${ }^{210-12}$ Basic focus of this study is to know, whether hemoglobin disorders play any role in the pregnancy outcome or not? None of the studies so far reported on pregnant women from India, have ever highlighted the contributions of maternal afflictions of hereditary hemolytic disorders [hemoglobinopathies, glucose-6-phosphate dehydrogenase deficiency (G6PD) of enzyme, hemolytic disease of the new born, etc.] for the high maternal morbidity, mortality and fetal loss in India, except a few studies earlier reported by us. $8,9,13,14$

Anemia in pregnancy is emerging as one of the most important causes of maternal complications, morbidity and offspring mortality in almost all the developing countries of the world including India. Patients suffering from sickle cell disease are generally anemic, and are susceptible to infections. Untreated infections cause aggravation of severity of the sickle cell disease, subsequently, leading to death. Infants affected with the disease may present with dactylitis, fever and overwhelming sepsis, chronic hemolytic anemia, jaundice, episodic vascular occlusive crises, hyposplenism, periodic splenic sequestration (which can be life
Correspondence: Ranbir S. Balgir, Department of Biochemistry, Regional Medical Research Centre for Tribals (Indian Council of Medical Research), Nagpur Road, Post Office: Garha, Jabalpur482003, Madhya Pradesh, India.

E-mail: balgirrs@yahoo.co.in

Key words: Prevalence; hemolytic anemia; hemoglobinopathies; hematological indices; pregnant women; Madhya Pradesh; central India.

Acknowledgements: the author is grateful to $\mathrm{Dr}$. V.M. Katoch, Secretary, Department of Health Research, Government of India and Director General, Indian Council of Medical Research, New Delhi for providing the necessary research facilities and the subjects for their kind cooperation. Author gratefully acknowledges Prof. Shashi Khare, Professor \& Head, Department of Obstetrics \& Gynecology, and Dean, Netaji Subhash Chandra Bose Medical College and Hospital, Jabalpur for referring the subjects for investigations. Thanks are also due to Mr. VK Kachhi and Mr. P. Patel, Laboratory Technicians for their technical support during the investigations.

Funding: Intra-mural, Regional Medical Research Centre (ICMR) Jabalpur, India.

Conflict of interest: the author declares no potential conflict of interest.

Received for publication: 31 July 2014.

Revision received: 10 June 2015.

Accepted for publication: 29 September 2015

This work is licensed under a Creative Commons Attribution 3.0 License (by-nc 3.0).

(C) Copyright R.S. Balgir 2015

Licensee PAGEPress, Italy

Thalassemia Reports 2015; 5:4644

doi:10.4081/thal.2015.4644

threatening in a small child) and bone marrow sepsis. Hemoglobin - the red pigment of red blood cells transports oxygen to different parts of the body. Any defect in hemoglobin structure leads to adverse functional properties of the red cells. Inadequate availability of oxygen to fetus also leads to abortion, miscarriage or stillbirth. The primary purpose of hemoglobinopathies screening in pregnant women is to identify the mothers and fetuses vulnerable to hemolytic anemia due to sickle cell disease and other abnormal hemoglobin variants for which early intervention has been shown to markedly reduce morbidity and mortality.

From research point of view, it is not known what is the status of hemoglobinopathies and what are the hemoglobin variants prevalent in pregnant women in central India? Hemoglobinopathies are one of the causes of hemolytic anemia in vulnerable people. To the best of our knowledge, no study pertaining to 
the prevalence of hemoglobin disorders in pregnant women is available from any part of India. The state of Madhya Pradesh falls under a sickle cell belt for the high prevalence of hemoglobinopathies [average: 7.04\%; range 0$34 \%$ in Madhya Pradesh ${ }^{15}$ ]. Keeping this state of affairs in mind, this study was designed with the aims and objectives: i) to find the prevalence of anemia and hemoglobinopathies (genetic burden) in pregnant women attending a tertiary hospital in central India; and ii) to determine the health status and hematological profile of pregnant women afflicted with hemoglobin disorders against normal controls in Central India.

\section{Materials and Methods}

This is a prospective cross-sectional study carried out in the Outpatient Department of Obstetrics and Gynecology, NSCB Medical College and Hospital, Jabalpur in central India. Pregnant women who visited for antenatal care check up were investigated. Each subject was requested to provide the background information such as name, age, residential address, reproductive history (abortion, miscarriage, stillbirth, etc.) if any, month of gestation, history of hospitalization if any, blood transfusion or pregnancy related complications if any, etc. Confirmed cases of sickle cell disorders or other hemoglobinopathies were formed our study group and the negatives (without hemoglobinopathies) were taken as control group. Cases suffering from other abnormalities were not included or referred to us by the concerned doctor. All those pregnant women who had iron or folic acid deficiency, etc. were treated and were given iron-folic acid and multi-vitamin supplementations by the attending and referring doctor of Gynecology Department of NSCB Medical College and Hospital, Jabalpur for improving the hematological indices, maternal health of the pregnant women, and for the proper development of the fetus. The study was carried out according to the ethical guidelines for biomedical research on human subjects.

Intravenous 2-3 mL blood samples of a cross-section of 416 pregnant women were collected using disposable syringes and needles in disodium salt of ethylene diamine tetraacetic acid (EDTA) coated vials after taking informed consent from each pregnant woman during the period from April 2013 to March 2014. Blood samples so collected were transported under wet ice-cold conditions to RMRCT, Jabalpur for laboratory investigations and were analyzed in Biochemistry laboratory following the standardized laboratory procedures and techniques. ${ }^{16,17}$ Hematological parameters were studied using an automated blood cell counter (Model $\mathrm{MS}_{5} 9$, Melet
Schloesing Laboratories, Cergy-Pontoise Cedex, France).

The sickling test was performed by using freshly prepared $2 \%$ sodium metabisulphite solution as a reducing agent for the absence or presence of sickle cell hemoglobin. ${ }^{16}$ Routine hemoglobin $(\mathrm{Hb})$ lysate electrophoresis was carried out on cellulose acetate membrane in Tris-EDTA-borate buffer at pH 8.9 and quantification of hemoglobin $\mathrm{A}_{2}$ fraction was done by elution method. ${ }^{17}$ The value of more than $3.5 \%$ of hemoglobin $\mathrm{A}_{2}$ fraction of adult hemoglobin was taken as cut off point for determining the $\beta$-thalassemia trait; and more than $10 \%$ of $\mathrm{A}_{2}$ as hemoglobin E. Estimation of fetal hemoglobin was carried out as described by Weatherall. ${ }^{17}$

The diagnosis of sickle cell/ $\beta$-thalassemia was based on findings of hemoglobin A, F, S and $\mathrm{A}_{2}$ on electrophoresis under acidic and alkaline media, elevated $\mathrm{Hb} \mathrm{A}_{2}$ levels (>3.5\%), and family study. Anemia was defined as per the World Health Organization (WHO) Report Guidelines. ${ }^{18}$ Before giving the biochemical and hematological investigations report to each pregnant woman; all the carriers/affected ladies were given genetic counseling. This study presented a comparative hematological picture of pregnant women against normal controls reflecting the status of reproductive health care in India.

Results obtained were statistically tested by performing student $t$ test and chi-square analysis to compare the normal with each diagnostic category for the difference between the two independent variables, and significance if any, was also indicated.

\section{Results}

In a cross-sectional study of 416 pregnant women screened for hemoglobinopathies referred from the Department of Gynecology and Obstetrics, Netaji Subhash Chandra Bose Medical College and Hospital, Jabalpur during the period from April 2013 to March 2014, alarmingly high prevalence of $12.26 \%$ of hemo- globinopathies was found in the present study, and the affliction with sickle cell trait being $7.45 \%$, followed by $\beta$-thalassemia trait (2.89\%), hemoglobin E trait (0.24\%), and sickle cell disease (1.68\%). About $88 \%$ of the pregnant women were found free of hemoglobinopathies. The women with sickle cell disorders constituted $9.13 \%$ of the total pregnant women investigated and reported for the first time from central India. There were 7 (1.68\%) pregnant women aged between 21 to 29 years, who were suffering from the homozygous sickle cell disease (Table 1).

All the pregnant women were graded for anemia according to the classification of WHO Report ${ }^{18}$ and data are presented in Table 2. It is apparent from table that the overall (average) $47.11 \%$ of the pregnant women had different grades of anemia with a range falling in between $45 \%$ to $66 \%$. However, $100 \%$ anemia persisted in those pregnant women who were suffering from homozygous sickle cell disease. The frequency of severe anemia was recorded to be $8.33 \%$ ( $\beta$-thalassemia trait), $9.32 \%$ (normal), $19.35 \%$ (sickle cell trait) and $71.43 \%$ (homozygous sickle cell disease) in pregnant women.

Table 3 shows the comparison of hematological indices of pregnant women with and without hemoglobinopathies. It has been observed that the values of hematological indices such as $\mathrm{Hb}$, red blood cell (RBC) and hematocrit (HCT) were much lower in homozygous sickle cell disease cases than in the normal cases.

\section{Discussion}

Hereditary hemolytic anemia, nutritional deficiencies (iron-folic acid deficiency, vita$\min B_{12}$, protein energy malnutrition, etc.), parasitic infections (malaria) and parasitic infestations (worms) play a major role in determining the pregnancy outcome in both underdeveloped and developing countries of the world. Among the hereditary hemolytic disorders: $\beta$-thalassemia syndrome, sickle cell disease, and G6PD enzyme deficiency, are the sig-

Table 1. Prevalence of hemoglobinopathies in pregnant women in a tertiary hospital (NSCB Medical College \& Hospital, Jabalpur) in Central India during April to March 2014.

\begin{tabular}{lccc} 
Pregnant women & No. & Percent & Prevalence of hemoglobinopathies \\
Normal & 365 & 87.74 & \\
Sickle cell trait & 31 & 7.45 & $12.26 \%$ \\
\hline Sickle cell disease & 7 & 1.68 & \\
Hemoglobin E trait & 1 & 0.24 & \\
\hline -thalassemia trait & 12 & 2.89 & \\
All hemoglobinopathies & 416 & 100.00 &
\end{tabular}


nificant contributors to anemia in pregnant women in tropical and subtropical countries including the India. The present study was focused on the prevalence of hemoglobinopathies in pregnant women attending a tertiary hospital in central India. For the first time, the study has revealed alarmingly high prevalence of hemoglobinopathies (12.26\%), with affliction of sickle cell trait (7.45\%), $\beta$ thalassemia trait (2.89\%), hemoglobin E trait $(0.24 \%)$, and sickle cell disease (1.68\%). About $88 \%$ of the pregnant women were found free of hemoglobinopathies. The women with sickle cell disorders constituted $9.13 \%$ of the total pregnant women, showing the magnificence magnitude of the health problem in central India. It is interesting to note the lower (reduced) prevalence of anemia (47.1\%, with a range of 45-66\%) among the pregnant women attending a tertiary hospital in central India than the Indian average of $72 \%$. This is a positive finding, which indicates that after providing all possible financial assistance to a dedi- cated team of community health workers through the Central Government's National Rural Health Mission (NRHM), Accredited Social Health Activists (ASHAs) and Janani Suraksha Yojna have all been effective instrumental in implicating the governmental policies and bringing improvement in maternal health care by reducing anemia in pregnant women through timely introducing micronutrient supplementations by the attending doctor, by approaching to a medical facility (in our case a Tertiary Hospital) for regular and timely antenatal care check up in Madhya Pradesh of central India. However, in those pregnant women who are suffering from homozygous sickle cell disease, $100 \%$ anemia is still existing (Table 2) due to the failure to raise the hemoglobin level even with iron-folic acid supplementations ascribable to inherited hemoglobin structural abnormalities. The frequency of severe anemia in pregnant women afflicted with $\beta$-thalassemia trait (8.33\%), normal $(9.32 \%)$, sickle cell trait $(19.35 \%)$ and homozygous sickle cell disease (71.43\%) is still very high. For the distribution of different grades of anemia, the difference between normal (without hemoglobinopathies) and homozygous sickle cell disease pregnant women is highly significant $(\mathrm{P}<0.001)$.

In general, in the normal pregnancy, blood volume increases, which results in a concomitant hemodilution. Although RBC mass increases during pregnancy, plasma volume increases more, resulting in a relative anemia. This hemodilution results in a physiologically lowered hemoglobin level, HCT value, and RBC count, but it has no effect on the mean corpuscular volume (MCV). A comparison of the hematological indices of these pregnant women has revealed that the pregnant women afflicted with sickle cell disorders have much reduced hemoglobin level, RBC count, MCV, HCT, and mean corpuscular hemoglobin; and raised leucocytosis than in the normal (without hemoglobinopathies) pregnant ladies (Table 3). Low profile of hematological indices

Table 2. Different grades of anemia in pregnant women with and without hemoglobinopathies.

\begin{tabular}{|c|c|c|c|c|c|}
\hline $\begin{array}{l}\text { Grades of anemia } \\
\text { (WHO Report 1989) }\end{array}$ & $\begin{array}{c}\text { Normal control } \\
\begin{array}{c}\mathrm{N}=365 \\
\text { No. }(\%)\end{array}\end{array}$ & $\begin{array}{l}\text { Sickle cell trait } \\
\begin{array}{c}\mathrm{N}=31 \\
\text { No. }(\%)\end{array}\end{array}$ & $\begin{array}{c}\text { Sickle cell disease* } \\
N=7^{\circ} \\
\text { No. }(\%)\end{array}$ & $\begin{array}{c}\text { Hemoglobin E trait } \\
\mathrm{N}=1 \\
\text { No. }(\%)\end{array}$ & $\begin{array}{c}\beta \text {-thalassemia trait } \\
\mathrm{N}=12 \\
\text { No. }(\%)\end{array}$ \\
\hline $\begin{array}{l}\text { Severe anemia } \\
(\mathrm{Hb}<7.0 \mathrm{~g} / \mathrm{dL})\end{array}$ & $34(9.32)$ & $6(19.35)$ & $5(71.43)$ & $0(0.00)$ & $1(8.33)$ \\
\hline $\begin{array}{l}\text { Moderate anemia } \\
\text { (Hb 7.1-10.0 g/dL) }\end{array}$ & 79 (21.64) & $8(25.81)$ & $2(28.57)$ & $1(100.00)$ & $3(25.00)$ \\
\hline $\begin{array}{l}\text { Mild anemia } \\
\text { (Hb 10.1-11.0 g/dL) }\end{array}$ & $50(13.70)$ & $4(12.90)$ & $0(0.00)$ & $0(0.00)$ & $3(25.00)$ \\
\hline $\begin{array}{l}\text { Normal } \\
(\mathrm{Hb}>11.1 \mathrm{~g} / \mathrm{dL})\end{array}$ & 202 (55.34) & $13(41.94)$ & $0(0.00)$ & $0(0.00)$ & 5 (41.67) \\
\hline
\end{tabular}

WHO, World Health Organization; Hb, hemoglobin. *Anemia in normal versus sickle cell disease cases significant at $\mathrm{P}<0.001$; ${ }^{\circ}$ age of pregnant women: $21,21,22,25,26,28$, and 29 years.

Table 3. Comparison of hematological indices of pregnant women with and without (Normal) hemoglobinopathies.

\begin{tabular}{|c|c|c|c|c|c|}
\hline $\begin{array}{l}\text { Grades of anemia } \\
\text { (WHO Report 1989) }\end{array}$ & $\begin{array}{c}\text { Normal } \\
N=365 \\
\text { Mean (SD) }\end{array}$ & $\begin{array}{c}\text { Sickle cell trait } \\
\qquad \begin{array}{c}\text { N=31 } \\
\text { Mean (SD) }\end{array}\end{array}$ & $\begin{array}{c}\text { Sickle cell disease } \\
\mathrm{N}=7^{\circ} \\
\text { Mean (SD) }\end{array}$ & $\begin{array}{c}\text { Hemoglobin E trait } \\
\mathrm{N}=1 \\
\text { Mean (SD) }\end{array}$ & $\begin{array}{c}\beta \text {-thalassemia trait } \\
\mathrm{N}=12 \\
\text { Mean (SD) }\end{array}$ \\
\hline $\mathrm{Hb}(\mathrm{g} / \mathrm{dL})$ & $10.60(2.41)$ & $9.81(2.72)$ & $5.20^{c}(2.40)$ & 8.40 & $10.80(2.91)$ \\
\hline $\mathrm{RBC}\left(\mathrm{x} 10^{3} / \mu \mathrm{L}\right)$ & $4.00(0.74)$ & $3.87(0.91)$ & $1.91^{\mathrm{c}}(0.99)$ & 4.00 & $4.06(0.70)$ \\
\hline MCV (fL) & $76.80(11.20)$ & $73.60(15.72)$ & $79.00(7.93)$ & 59.80 & $75.30(12.10)$ \\
\hline HCT (\%) & $30.70(6.25)$ & $27.90^{\mathrm{a}}(7.03)$ & $15.00^{c}(6.70)$ & 23.90 & $30.73(6.46)$ \\
\hline $\mathrm{MCH}(\mathrm{pg})$ & $26.70(4.72)$ & $25.66(6.38)$ & $27.10(3.91)$ & 21.10 & $26.30(5.98)$ \\
\hline $\mathrm{MCHC}(\mathrm{g} / \mathrm{dL})$ & $34.40(2.69)$ & $34.59(2.74)$ & $34.30(3.40)$ & 35.30 & $34.69(3.45)$ \\
\hline RDW (\%) & $13.10(5.84)$ & $13.20(1.87)$ & $13.30(1.78)$ & 16.30 & $13.40(0.72)$ \\
\hline $\mathrm{WBC}\left(\mathrm{x} 10^{3} / \mu \mathrm{L}\right)$ & $9.00(5.25)$ & $9.07(3.03)$ & $11.60^{\mathrm{b}}(2.96)$ & 9.50 & $9.22(1.75)$ \\
\hline Sickling & -ve & $+\mathrm{ve}$ & $+\mathrm{ve}$ & -ve & -ve \\
\hline Electrophoresis (pH 8.9) & $\mathrm{AA}$ & AS & SS & $\mathrm{AE}$ & $\mathrm{AA}_{2}$ \\
\hline $\mathrm{Hb} \mathrm{A}_{2} / \mathrm{E}(\%)$ & $2.50(0.39)$ & $2.54(0.26)$ & $2.39^{\mathrm{a}}(0.12)$ & 25.00 & $5.72^{\mathrm{c}}(1.12)$ \\
\hline $\mathrm{Hb}$ fetal $(\%)$ & $0.50(0.10)$ & $1.20^{\circ}(0.35)$ & $20.00^{\circ}(10.00)$ & 1.20 & $1.81^{\mathrm{c}}(1.02)$ \\
\hline
\end{tabular}

$\mathrm{Hb}$, hemoglobin; RBC, red blood cells count; MCV, mean corpuscular volume; HCT, hematocrit; MCH, mean corpuscular hemoglobin; MCHC, mean corpuscular hemoglobin concentration; RDW, red cell distribution width; WBC, white blood cells count. Difference between normal versus different diagnostic categories significant at: ${ }^{\mathrm{P}}<0.05 ;{ }^{\mathrm{b}} \mathrm{P}<0.01 ;{ }^{\mathrm{P}}<0.001$. 
in general do not show significant variations between pregnant women with (carrier cases) and without hemoglobin disorders and indicate very poor health status. Even normal pregnant women had reduced red cell indices due to iron-folic acid deficiency, mal- and undernutrition, and other parasitic infections/infestations, etc. However, there was a statistically significant reduction in hemoglobin level $(\mathrm{P}<0.001), \mathrm{RBC}$ counts $(\mathrm{P}<0.001)$, and HCT $(\mathrm{P}<0.001)$; and elevation of leucocytosis $(\mathrm{P}<0.01)$, and fetal hemoglobin $(\mathrm{P}<0.001)$ in patients of homozygous sickle cell disease than in the normal control (without hemoglobinopathies) pregnant women (Table 3 ). Quantitatively the hemoglobin $\mathrm{A}_{2}$ was raised in $\beta$-thalassemia trait $(\mathrm{P}<0.001) \quad$ pregnant women than in the normal ladies.

Iron deficiency anemia accounts for 75-95\% of the cases of anemia in pregnant women. Inadequate supply of oxygen to fetus leads to abortion, miscarriage or stillbirth. A woman who is pregnant often has insufficient iron stores to meet the demands of pregnancy. In an iron-replete population, anemia is a value less than the fifth percentile, and is a hemoglobin level of $11 \mathrm{~g} / \mathrm{dL}$ or less in the first trimester, $10.5 \mathrm{~g} / \mathrm{dL}$ or less in the second trimester, and $11 \mathrm{~g} / \mathrm{dL}$ or less in the third trimester. Many investigators define anemia in a patient who is pregnant as an $\mathrm{Hb}$ value lower than $\mathbf{1 0 . 5}$ $\mathrm{g} / \mathrm{dL}$, as opposed to the reference range of 14 $\mathrm{g} / \mathrm{dL}$ in a patient who is not pregnant. Treatment with $1 \mathrm{mg}$ folic acid and daily iron is helpful when deficiencies are noted. ${ }^{19}$ Encourage pregnant women to supplement their diet with $60 \mathrm{mg}$ of elemental iron daily. An MCV less than $80 \mathrm{mg} / \mathrm{dL}$ and hypochromia of the RBCs should prompt further studies, including total iron-binding capacity, ferritin levels, and $\mathrm{Hb}$ electrophoresis if iron deficiency is excluded. Clinical symptoms of iron deficiency anemia include: fatigue, headache, restless legs syndrome, and pica (in extreme situations). Treatment consists of additional supplementation with oral iron sulphate (320 mg, 1-3 times daily). Once-daily administration is preferable because more frequent iron supplementation can cause constipation. The clinical consequences of iron deficiency anemia include preterm delivery, perinatal mortality, and postpartum depression. Fetal and neonatal consequences include low birth weight, and poor mental and psychomotor performance. ${ }^{20}$ It was envisaged to bring awareness among the pregnant women through genetic counseling about the genetic disorders and their causal effects on health. Their eradication is necessary because they are not curable but preventable through carrier detection, prenatal diagnosis, and education and genetic counseling.

\section{Summary and Conclusions}

A cross-section of 416 pregnant women visiting NSCB Medical College and Hospital, Jabalpur in Central India for antenatal care check up, were investigated for the prevalence of hemoglobinopathies during April to March 2014. Out of a total of 416 pregnant women studied, the prevalence of hemoglobinopathies was found to be very high (12.26\%) including the contribution of the sickle cell disorders, being $9.13 \%$. Major hemoglobinopathies detected were: sickle cell trait (7.45\%), sickle cell disease (1.68\%), $\beta$-thalassemia trait (2.89\%), and hemoglobin E trait (0.24\%).

Overall the anemia prevalence was found to be $47.11 \%$ in the pregnant women with a range between $45-66 \%$, showing improvement in maternal health care and reduced anemia. Reduced values of hematological indices were noted in pregnant women afflicted with hemoglobin disorders than the normal (without hemoglobin disorders) controls. Anemia in pregnancy, in general, is associated with the adverse consequences for both the mother and the fetus. Adverse consequences of maternal anemia may affect not only the neonate and infant for poor intrauterine growth, prematurity and low birth weight and high perinatal mortality but also increase the risk of non-communicable diseases when the child grows into an adult life and risk of low birth weight even in the next generation. Immuno-depression in anemic women renders them more susceptible to infections especially to urinary tract infections, and to increased morbidity affecting the course and outcome of pregnancy.

Low profile of hematological indices do not show significant variations between pregnant women with (in carrier cases) and without hemoglobinopathies, indicating very poor health status of pregnant women in general.

Mandatory awareness for consumption of balanced diet, comprehensive clinical management, and genetic/marriage counseling after prenatal diagnosis are highly essential to ameliorate the sufferings of afflicted (especially pregnant) women. Poverty, ignorance, nonavailability and/or failure to utilize the available medical health facilities are shown to be associated with maternal anemia, and maternal and perinatal morbidity, and mortality in the rural population of central India.

A more vigorous and realistic campaign of prophylactic regime of supplementations for these pregnant women and child health care is suggested.

[Thalassemia Reports 2015; 5:4644]

\section{References}

1. Sinha M, Panigrahi I, Shukla J, et al. Spectrum of anemia in pregnant Indian women and importance of antenatal screening. Indian $\mathrm{J}$ Pathol Microbiol 2006;49:373-75.

2. Bentley ME, Griffiths PL. The burden of anemia among women in India. Eur J Clin Nutr 2003;57:52-60.

3. Sharma A, Patnaik R, Garg S, et al. Detection and management of anaemia in pregnancy in an urban primary health care institution. Indian J Med Res 2008;128:45-51.

4. Susheela AK, Mondal NK, Gupta Rashmi, et al. Effective intervention approach to control anaemia in pregnant women. Curr Sci 2010;98:1320-30.

5. DeMayer EM, Tegman A. Prevalence of anaemia in the world. World Health Org Quart 1998; 38:302-16.

6. Ezzati M, Lopus AD, Dogers A, et al. Selected major risk factors and global and regional burden of disease. Lancet 2002;360:1347-60.

7. Kalaivani K. Prevalence and consequences of anemia in pregnancy. Indian J Med Res 2009;130:627-33.

8. Balgir RS, Dash BP, Das RK. Fetal outcome and childhood mortality in offspring of mothers with sickle cell trait and disease. Indian J Pediatr 1997;64:79-84.

9. Balgir RS. Infant mortality and reproductive wastage associated with different genotypes of hemoglobinopathies in Orissa, India. Ann Hum Biol 2007;34:16-25.

10. Narasinga Rao BS. Anemia and micronutrient deficiency. Natl Med J India 2003;16:46-50.

11. Kapil U, Pathak P, Tandon M, et al. Micronutrient deficiency disorders amongst pregnant women in three urban slum communities of Delhi. Indian Pediatr 1999;36:983-9.

12. Khosla AH, Dahiya P, Dahiya K. Burden of chronic severe anemia in obstetric patients in rural north India. Indian J Med Sci 2002;56:222-4.

13. Balgir RS. Clinical genetics and hematological profile of sickle cell cases in twenty families of Orissa. Indian J Hematol Blood Transf 2006;22:45-52.

14. Balgir RS. Aberrant heterosis in hemoglobinopathies with special reference to $\beta$ thalassemia and structurally abnormal hemoglobins $\mathrm{E}$ and $\mathrm{S}$ in Orissa, India. J Clin Diagn Res 2007;1:122-30.

15. Singh N, Balgir RS, Saha KB, et al. Tribal health in retrospect: Experiences from multidisciplinary research activities at RMRCT. Jabalpur: RMRCT (ICMR); 2009. pp 11-26.

16. Dacie JV, Lewis, SM. Practical haematol- 
ogy, 7th ed. Edinburgh: Churchill Livingstone; 1991. pp 227-257.

17. Weatherall DJ. Hematologic methods. In: Weatherall DJ, ed. Methods in hematology: the thalassemias. Vol. 6. New York: Churchill Livingstone; 1983. pp 27-53.

18. World Health Organization Report.
Preventing and controlling iron deficiency anemia through primary health care. Geneva: World Health Organization; 1989.

19. Pena-Rosas JP, Viteri FE. Effects of routine oral iron supplementation with or without folic acid for women during pregnancy. Cochrane Database Syst Rev
2006;3:CD004736.

20. Ebrahim SH, Kulkarni R, Parker C, et al. Blood disorders among women: Implications for preconception care. Am J Prevent Med 2010;38:S459-67. 